\title{
Tricuspid paravalvular leak closure with a paravalvular leak device
}

\section{Oleg Polonetsky¹, Valery Stelmashok ${ }^{1}$, Tatiana Sevruk ${ }^{1}$, Alena Kurlianskaya ${ }^{1}$, Piotr Pysz ${ }^{2}$, Grzegorz Smolka²}

${ }^{1}$ Republican Scientific and Practical Centre "Cardiology”, Minsk, Belarus

${ }^{2} 3^{\text {rd }}$ Department of Cardiology, Medical University of Silesia, Katowice, Poland

Adv Interv Cardiol 2017; 13, 3 (49): 273-274

DOI: https://doi.org/10.5114/aic.2017.70202

A 69-year-old man, with a permanent pacemaker (PM) and a tricuspid bioprosthesis implanted 6 years ago, was admitted due to gradual exacerbation of heart failure symptoms to NYHA class III. Transthoracic (TTE) and transesophageal (TEE) echocardiography revealed proper function of bioprosthesis leaflets accompanied by the presence of severe paravalvular leak (PVL) with the PM lead crossing its channel. The paravalvular backflow velocity was $3.3 \mathrm{~m} / \mathrm{s}$ with a calculated right ventricle (RV) to right atrium (RA) gradient of $43 \mathrm{~mm} \mathrm{Hg}$ and regurgitant volume of $45 \mathrm{ml}$ on TTE. On three-dimensional (3D) TEE the PVL was oval-shaped with dimensions of $7 \times 10 \mathrm{~mm}$ (Figure $1 \mathrm{~A}$ ). The interatrial septum (IAS) appeared to be shoved towards the left atrium (LA) with reversed, rightto-left shunt across the patent foramen ovale (PFO). No significant pathology was visualized within the left heart chambers. The Heart Team consulted the patient and a transcatheter closure was scheduled. The procedure was performed in general anesthesia under real time (RT) 3D TEE and fluoroscopy guidance. A rectangular waist-type $8 \times 4 \mathrm{~mm}$ Paravalvular Leak Device [1] (PLD, Occlutech $\mathrm{GmbH}$ ) was implanted with a standard vendor

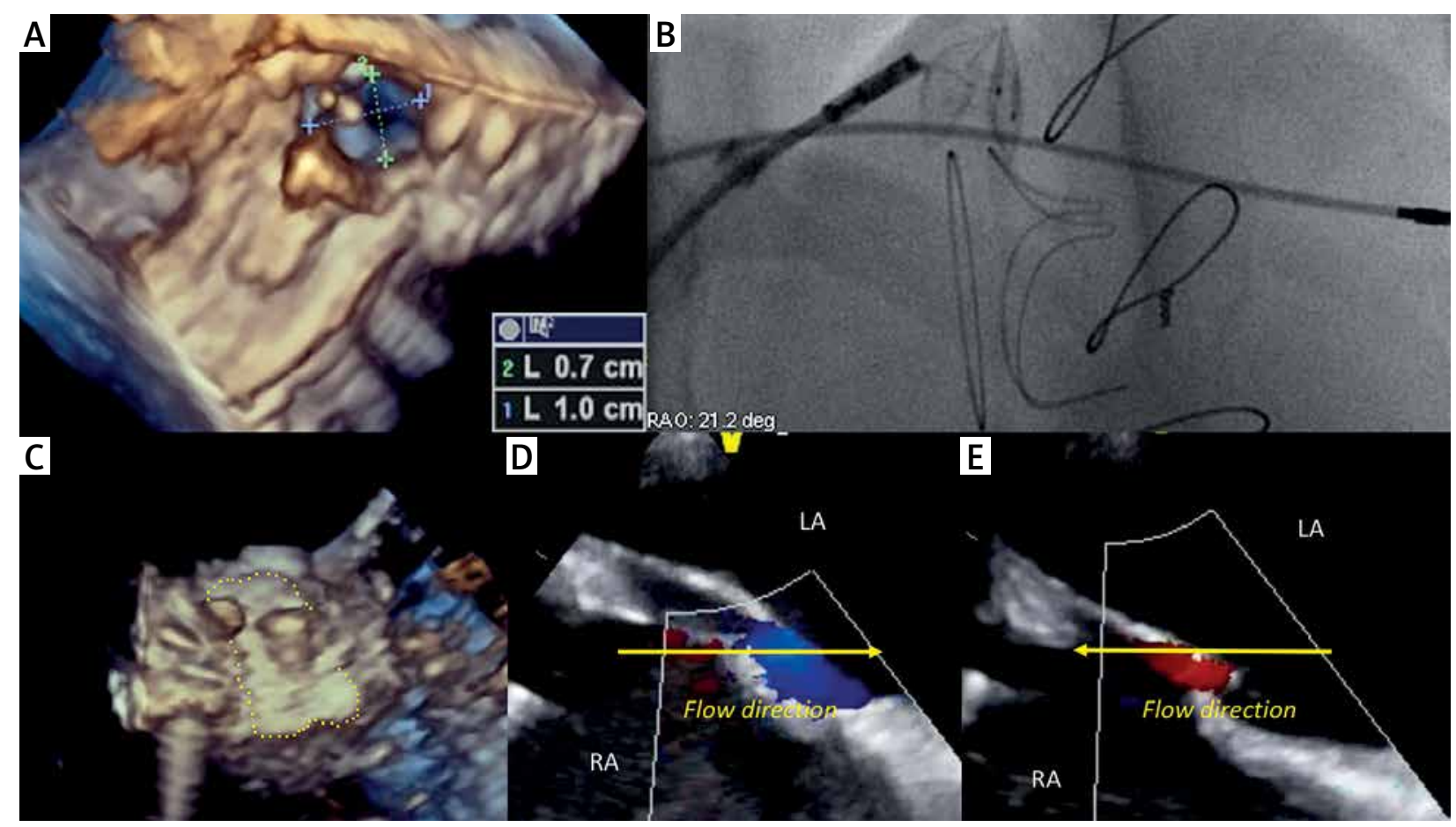

Figure 1. Intraprocedural imaging: A, C - RT 3D TEE volume rendering, B - fluoroscopy, D, E - 2D TEE color flow mapping

\section{Corresponding author:}

Grzegorz Smolka MD, PhD, FESC, $3^{\text {rd }}$ Department of Cardiology, Medical University of Silesia, 45-47 Ziołowa St, 40-635 Katowice, Poland, phone: +48 501201 622, e-mail: grsm18@wp.pl

Received: 19.02.2017, accepted: 19.03.2017. 
delivery system as shown in Figure 1 B. It was chosen as best fitting the PVL anatomy visualized by RT 3D TEE (Figure $1 \mathrm{C}$ ). After deployment of the occluder only trivial residual paravalvular flow was present in the area where the PLD bordered the PM lead. Remarkably, within minutes after PLD implantation, the IAS returned to a neutral position between the atria and shunting across the PFO changed direction to left-to-right - Figure $1 \mathrm{D}$ (baseline) and Figure $1 \mathrm{E}$ (post-procedural). No complications occurred and the patient was discharged from hospital on the next day. In 4-week follow-up the patient's functional capacity improved to NYHA class II. On TTE the RV to RA gradient remained unchanged but the regurgitant volume of residual paravalvular flow was reduced to $12 \mathrm{ml}$.

\section{Conflict of interest}

Grzegorz Smolka has a proctorship contract with Occlutech International AB. Others authors declare no conflict of interest.

\section{References}

1. Smolka G, Pysz P, Kozlowski M, et al. Transcatheter closure of paravalvular leaks using a paravalvular leak device - a prospective Polish registry. Adv Interv Cardiol 2016; 12: 128-34. 